\title{
Cell cycle checkpoint control
}

\author{
1 Department of Biochemistry, Faculty of Medicine, \\ The University of Tokyo, Japan \\ 2 Corresponding author
}

Hiroshi Murakami ${ }^{1}$ and Hiroto Okayama ${ }^{1,2}$

Accepted 1 March 1997

Abbreviations: ORC, origin-recognition complex; RF-C, replication factor-C; $\mathrm{HU}$, hydroxyurea; ATM, ataxia telangiectasia mutated gene product; CAK, CDC2-activating kinase

\begin{abstract}
Genetic instability is considered to be a major driving force of malignancy of cancer cells, and at least some of cancer-associated genetic instability is known to be caused by defects in the cell cycle checkpoint control. Patients of the cancer-prone genetic disorder ataxia telangiectagia frequently develop malignant lymphoma and their cells are defective in $\gamma$-irradiation responsive checkpoint control, whereas cells inactivated for the p53 recessive oncoprotein are defective in DNA damageinduced checkpoint control and develop genetic instability. Cells contain two major cell cycle checkpoint control systems: DNA-replication checkpoint, DNA-damage checkpoint. These checkpoint systems are thought to consist of three functionally distinct components: sensors, checkpoint signal transducers and cell cycle effectors. Recent rapid progress in the identification of these components is beginning to prove this conceptual model and the generality of the checkpoint system among eukaryotes. The full understanding of the cell cycle checkpoint control system will provide deeper insights into the highly complex mechanisms of carcinogenesis and highlight possible targets for cancer therapy.
\end{abstract}

Keywords: cell cycle, cancer, ataxia telangietagia, DNA damage, DNA replication

\section{Introduction}

One of the key properties of malignantly transformed cells is genetic instability. Genetic instability itself, however, has no contribution to malignant phenotypes but is considered to act as a powerful engine driving activation and inactivation of a variety of oncogenes and recessive oncogenes, which ultimately lead to the expression of malignant phenotypes. Recent advances in cell cycle research indicate that a defect in a checkpoint control may be responsible for the genetic instability of at least some cancer cells (Hartwell and Kastan, 1994). The p53 recessive oncogene, which is inactivated in a variety of cancer cells, is actually required for genetic stability and $\gamma$-irradiation induced G1 checkpoint arrest (Ko and Prives, 1996; Sherr, 1996), whereas ATM, the causative gene for cancerprone ataxia telangiectasia, structurally resembles a checkpoint gene in yeast and is essential for $\gamma$ irradiation induced checkpoint arrest (Savitsky et al., 1995; Elledge, 1996; Sherr, 1996).

The current understanding of the mechanisms of cell cycle checkpoint control is still fragmentary and far from complete, yet in the past few years a remarkable progress has been made regarding its key elements. In this review, we outline the current understanding of general cell cycle checkpoint control and discuss its implication to cancer research.

\section{Checkpoint controls in the cell cycle}

Duplication of the genome and its faithful transmittance to the daughter cells are vital to the propagation of all organisms. The cell cycle-associated checkpoint controls have been evolved as a surveillance mechanism to ensure the proper occurrence of these fundamental cellular events (Hartwell and Weinert, 1989). It monitors whether or not the genetic information is completely duplicated or thoroughly repaired if it is damaged and controls cell cycle progression, much like a quality control in a factory, they have to be produced in an orderly fashion and checked for quality before shipment. Cells contain several distinct checkpoint controls (Nurse, 1994; Diffley, 1996; Edgar and Lehner, 1996; Elledge, 1996; King et al., 1996; Nasmyth, 1996; Okayama et al., 1996; Sherr, 1996; Stillman, 1996). One called DNA replication checkpoint control is present to prevent entry into mitosis during $S$ phase. One called DNA damage checkpoint control is to block cell cycle progression until damage is completely repaired. There are other types of checkpoint controls, which ensure duplication of the genome only once per cycle and faithful progression of mitosis. Moreover, all the cell cycle controls by various extracellular and intracellular signals, such as those for nutrient availability, cell size and cell-cell interactions, could also be considered to be one type of checkpoint control. Because of their high relevance to 
carcinogenesis, we like to focus on DNA replication-, DNA damage- and endoreplication-checkpoint controls in this review.

Conceptually, these checkpoint control systems are thought to be made up of three functionally distinct components: a sensor(s), a checkpoint signal transducer(s) and a cell cycle effector(s). The sensor would detect, via a specific object(s), the events and, if the events are in progress, generate checkpoint signal, which is mediated by the signal transducer(s) and controls the effector to block cell cycle progression. The effector is actually a key component of the cell cycle progression machinery. In this concept, the sensor would generally have no function other than monitoring the event and the checkpoint signal generated by the sensor always acts to block cell cycle progression. If the object(s) were absent or the sensor(s) were inactivated, the checkpoint signal would not be generated. Consequently, cells in which the sensor or the object is missing would display checkpoint defects. Recent identification of key checkpoint factors began to prove this conceptual model.

The components of the checkpoint control system have been identified in the fission yeast Schizosaccharomyces pombe, the budding yeast Saccharomyces cerevisiae, Aspergillus nidulans, mammal and other

Table 1. Checkpoint related genes in yeast

\begin{tabular}{lcccccc}
\hline S. pombe & $\begin{array}{c}\text { DNA } \\
\text { replication }\end{array}$ & $\begin{array}{c}\text { DNA } \\
\text { damage }\end{array}$ & Activity & $\begin{array}{c}\text { Putative S. cerevisiae } \\
\text { counterpart }\end{array}$ & $\begin{array}{c}\text { DNA } \\
\text { replication }\end{array}$ & $\begin{array}{c}\text { DNA } \\
\text { damage }\end{array}$ \\
\hline rad1 & + & + & Nuclease & RAD17 & - & + \\
rad3 & + & + & Pl-kinase & MEC1 & + & $?$ \\
rad9 & + & + & $?$ & RAD24 & - & + \\
rad17 & + & + & RFC-related & $?$ & $?$ \\
rad26 & + & + & $?$ & $?$ & $?$ & $?$ \\
hus1 & + & + & $?$ & BMH1, BMH2 & $?$ & $?$ \\
rad24, rad25 & - & + & 14-3-3 & $?$ & $?$ \\
chk1 & - & + & protein kinase & RAD53 & + & $?$ \\
cds1 & + & - & protein kinase & RAD9 & + & + \\
$?$ & $?$ & $?$ & $?$ & MEC3 & + & + \\
$?$
\end{tabular}

Fission yeast

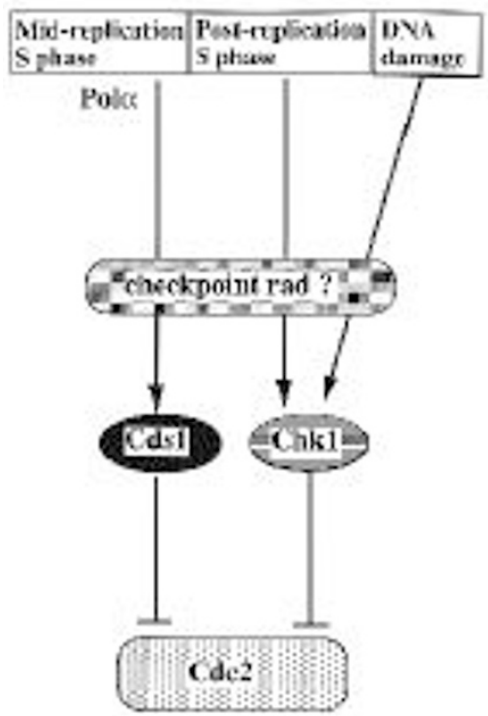

Budding yeast

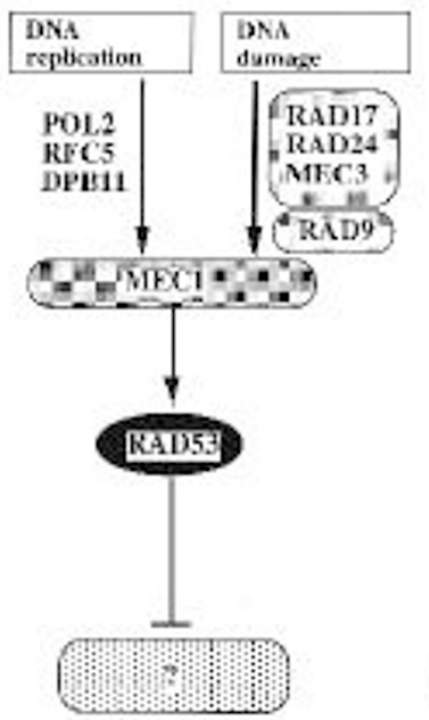

Mammalian cells

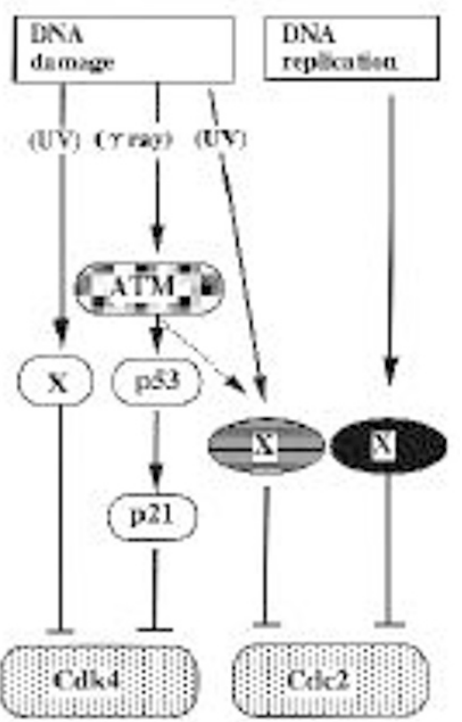

$\mathrm{G}_{1}$ coll cycle arrest
Gz cell cyck arrest
Figure 1. Checkpoint signal transduction. 
organisms (Table 1; Figure 1). The former three organisms are genetically tractable and have many features common to mammals. The important feature of the fission yeast as well as most of other eukaryotes is that mitosis and other mitotic events never start until the completion of S phase. On the contrary, in budding yeast, some mitotic events, such as spindle pole body duplication, initiate even before the onset of $S$ phase. Since such difference in cell cycle progression would profoundly affect the way of checkpoint regulation, the objects to be sensed and the cell cycle targets for the checkpoint control might entirely differ between budding yeast and other organisms. We, therefore, will describe the fission yeast system as the primary example and discuss those of budding yeast, A. nidulans and mammals.

\section{DNA replication-monitoring checkpoint control}

How the DNA replication checkpoint system monitors $S$ phase has begun to be understood. The recent identification of a major sensor monitoring $S$ phase has revealed that $S$ phase is monitored in three separated sub-phases: pre-replication, mid-replication and postreplication (Murakami and Okayama, 1995).

\section{Pre-replication S phase}

The primary cellular event in this phase is activation of origins of replication which is achieved by their association with the pre-replicative complex that is composed of origin-recognition complex (ORC), MCM proteins, Cdc18 (Cdc6 homologue) and probably a Cdc7-related protein kinase (Diffley, 1996; Stillman, 1996). Interestingly, fission yeast cells deleted for a component of ORC (Muzi-Falconi and Kelly, 1995; Grallert and Nurse, 1996; Leatherwood et al., 1996), Cdc7-related kinase (Masai et al., 1995), a MCM homologue (Maiorano et al., 1996), or Cdc18 (Kelly et al., 1993) enter mitosis without DNA synthesis, indicating that the pre-replication complex is likely to be a major object detected by a checkpoint sensor. However, the nature of the sensor is currently unknown. A cut5- mutant, which arrests before DNA replication upon shift to the nonpermissive temperature, is also defective in checkpoint control (Saka and Yanagida, 1993). But, the function of Cut5 and its possible relation to the pre-replication complex is not known at present.

\section{Mid-replication S phase}

In this phase, DNA is synthesized by several functionally distinct polymerases. DNA polymerase $\alpha$ initiates DNA replication as a primer complex and synthesizes the lagging strand whereas DNA polymerase $\delta$ synthesizes the leading strand as well as elongates the lagging strand (Sugino, 1995). Fission yeast cells deleted for DNA polymerase $\alpha$ enter mitosis without DNA synthesis (D'Urso et al., 1995). In contrast, cells deleted for DNA polymerase $\delta$ or $\varepsilon$ arrest in $S$ phase and never proceed into mitosis (D'Urso et al., 1995; D'Urso and Nurse, 1996). In addition, cells deleted for Cdc1, a subunit of DNA polymerase $\delta$, have intact checkpoint function (MacNeill et al., 1996). Furthermore, Cdc27, a factor associated with Cdc1, is not involved in checkpoint control (MacNeill et al., 1996). Thus, DNA polymerase $\alpha$ is likely to be an object detected by a sensor. Recently, a factor that fits the criteria of a checkpoint sensor in this sub-phase was identified. It is Cds1 kinase (Murakami and Okayama, 1995). The $c d s 1^{+}$gene was isolated as a multicopy suppressor of a temperature-sensitive DNA polymerase $\alpha$ mutant. It encodes a serine/threonine protein kinase homologous with Rad53 in budding yeast. Cells deleted for $c d s 1^{+}$are viable and have no detectable defect in DNA synthesis, but display a checkpoint defect to DNA synthesis inhibitors but not to DNA damage. When treated with hydroxyurea $(\mathrm{HU}$, an inhibitor of ribonucleotide reductase, the key enzyme for the synthesis of deoxyribonucleotides), cells lacking Cds1 initially arrest in early S. However, they prematurely enter mitosis as soon as DNA polymerase $\alpha$ starts synthesizing DNA as an enough amount of deoxyribonucleotides accumulates due to leaky inhibition of ribonucleotide reductase. Thus, the checkpoint defect of cells lacking Cds 1 is closely associated with the start of DNA synthesis, well matching with the expected properties of a checkpoint sensor. The object monitored by Cds 1 is likely to be only DNA polymerase $\alpha$ because Cds 1 is not required for checkpoint control when cell cycle progression is inhibited by inactivation of other factors essential for $S$ phase progression (Murakami and Okayama, 1995; Murakami and Okayama, unpublished results).

It is not known whether the checkpoint signal generated by Cds1 is directly transmitted to the cell cycle target or mediated by some factor(s) although several checkpoint rad genes have been known. The cell mutants of the checkpoint rad genes were initially isolated as those highly sensitive to irradiation, but subsequently found to be defective in damageresponsive checkpoint control (Al-Khodairy and Carr, 1992; Rowley et al., 1992a). $\operatorname{rad}^{+}, \operatorname{rad}^{+}, \operatorname{rad}^{+}$, $\operatorname{rad} 17^{+}, \operatorname{rad} 26^{+}$and $h u s 1^{+}$are among them (Enoch et al., 1992; Rowley et al., 1992a; Al-Khodairy and Carr, 1992; Al-Khodairy et al., 1994). Interestingly, these genes are also required for DNA replication checkpoint controls, and their mutants show very similar checkpoint defects and viability loss to both ultraviolet (UV) irradiation and hydroxyurea treatment (Al-Khodairy and Carr, 1992; Enoch et al., 1992; Rowley et al., 1992a; AlKhodairy et al., 1994). There is no evidence to indicate that any one of them acts upstream or downstream of 
the others. High level expression of $\operatorname{rad}^{+}$and $\operatorname{rad}^{+}$is unable to rescue the other checkpoint rad mutants (Murakami and Okayama, unpublished data). Since the mutants of these rad genes have similar defects in checkpoint function and none of them shows any clear upstream-downstream relationship, their products might function as a large protein complex. But, there is no biochemical evidence to support this possibility.

There is, however, a clear interaction between $c d s 1^{+}$ and these checkpoint rad genes. High level expression of $c d s 1^{+}$efficiently rescues the DNA replication checkpoint defect of at least $\mathrm{rad}^{+}, \mathrm{rad}^{+}$and $\mathrm{rad} 9^{+}$mutants (Murakami and Okayama, 1995). However, this rescue is specific to DNA replication checkpoint defect, and the similar high expression of $c d s 1^{+}$is unable to rescue the DNA damage checkpoint defect of these mutants. Such relationship holds true for $\mathrm{chk} 1^{+}\left(\operatorname{rad} 27^{+}\right)$but for their DNA damage checkpoint defects (see below for chk $1^{+}$). Overexpression of $c h k 1^{+}$rescues the DNA damage checkpoint defect (Walworth et al., 1993) but not the DNA replication checkpoint defect of these mutants (Murakami and Okayama, unpublished observations). Regarding the functions of the checkpoint sensor and these checkpoint rad genes, these observations suggest that simple overproduction of a sensor would not generate checkpoint signals unless the proper object is present and also in action.

Some of the checkpoint Rad proteins, however, have interesting structural features or similarity to some known proteins. Rad3, a putative phosphatidylinositol 3kinase, has a significant functional and structural similarity with, and therefore is considered to be a homologue of, the ataxia telangiectasia mutated gene product (ATM) in mammals (Savitsky et al, 1995). Rad17 protein shows a limited homology to replication factor-C (RF-C), an accessory factor for DNA polymerases $\delta$ and $\varepsilon$ (Griffiths et al., 1995). It is not clear whether its similarity to RF-C is meaningful because the mutant of at least DNA polymerases $\delta$ are intact in checkpoint control as already described. In addition, Rad1 protein has a homology to a nuclease (Lydall and Weinert, 1995; Siede et al., 1996a) whereas Rad9 (Lieberman et al., 1992) and Rad26 (Al-Khodairy et al., 1994) have no significant homology with any known proteins.

In budding yeast, the objects monitored by checkpoint sensors seem radically different from those in fission yeast. POL2 (DNA polymerase $\varepsilon$ ) (Navas et al., 1995), DPB11 (Araki et al., 1995) and RFC5 (Sugimoto et al., 1996) are known to be required for replication checkpoint, and cells with a point mutation of POL2 fail to arrest in response to $\mathrm{HU}$ but not to DNA damage. In addition, DPB11, essential for DNA replication, is required for checkpoint arrest to $\mathrm{HU}$. This protein is homologous with Cut5 in fission yeast that seems to be involved in some checkpoint pathway and has a genetic interaction with POL2. On the other hand, Rfc5 protein is a subunit of multiprotein complex called RF-C. These observations suggest that, unlike in fission yeast, DNA polymerase $\varepsilon$ is a potential candidate for an object for a DNA replication checkpoint sensor in this organism. This radical difference in the checkpoint sensing objects between the two organisms may reflect the difference in the control of the onset of mitosis.

The budding yeast mutant of RAD53 (SPK1, MEC2, SAD1), a kinase structurally similar to Cds1, is defective in both DNA replication and damage checkpoint control, but unlike Cds1, it is essential for viability (Stern et al., 1991; Allen et al., 1994; Weinert et al., 1994). Cells deleted for RAD53 die with large buds, suggesting that RAD53 is required for $S$ phase progression (Zheng et al., 1993). The reason for RAD53 requirement for $S$ phase progression is unknown. MEC1 (ESR1, SAD3), a homologue of ATM in humans and Rad3 in fission yeast, is involved in both DNA replication and DNA damage checkpoint controls (Kato and Ogawa, 1994; Weinert et al., 1994; Siede et al., 1996a). MEC1 is also essential for viability, but why it is required for viability remains unknown. The lethality of mec1 mutation is rescued by overexpression of RAD53 and phosphorylation of Rad53 protein is dependent on MEC 1 , suggesting that RAD53 acts downstream of MEC1 (Sanchez et al., 1996; Sun et al., 1996). In addition, overproduction of Rad53 protein rescues a $r f c 5$ mutation, similarly suggesting that Rad53 kinase acts downstream of RFC5 (Sugimoto et al., 1996).

\section{Post-replication S phase}

It is not known what determines the completion of $S$ phase and what factors are required for this. At the end of DNA replication, gaps and nicks in the DNA strand have to be sealed by DNA polymerase $\delta$ and DNA ligase. Therefore, at least such steps would be a potential candidate for the objects for checkpoint monitoring. However, such enzymes are unlikely to be the objects. As already described, these mutants have no detectable checkpoint defects. Unlike the prereplication and mid-replication $S$ phase, this stage of $S$ phase seem to be monitored via a DNA structure rather than some specific enzymes and protein factors involved.

The $c h k 1^{+}$gene was initially isolated by phenotypic suppression of a cold sensitive cdc2 mutant and found to play an important role in DNA damage checkpoint control and checkpoint control for nicked DNA induced by inactivation of DNA ligase (Walworth et al., 1993). Subsequently, this factor was found to be also essential for checkpoint control during $S$ arrest by inactivation of DNA polymerase $\delta$ (Francesconi et al., 1995). Furthermore, this gene is required for checkpoint control at the arrest points of the $c d c 1$ (a subunit for Pole), cdc19 (a $\mathrm{mcm}$ homologue), cdc21 (a mcm homologue), cdc24 
(essential for S phase progression) and cdc27 (binds Cdc1) mutants (Carr et al., 1995). Perhaps, at these arrest points, unrepaired nicks and gaps are left on the DNA strands. Whether Chk1 protein is a sensor of these aberrant structures of DNA or simply a signal transducer remains to be answered. Regarding its unique function, however, it is noteworthy that Chk1 contains a kinase domain as well as a leucine zipper motif which is essential for activity (Murakami and Okayama, unpublished observation).

\section{Cell cycle target for checkpoint control}

A key cell cycle target for the checkpoint signal is Cdc2 (Cdk1) kinase, which plays a central role in the onset and progression of mitosis in virtually all eukaryotic cells (Figure 2, 3) (Nurse, 1990; Okayama et al., 1996). For its mitotic activity, Cdc2 requires association with cyclin B (Moreno et al., 1989) and phosphorylation on the Thr 167 residue performed by CDC2-activating kinase
(CAK) (Gould et al., 1991; Buck et al., 1995; Damagnez et al., 1995). The timing of Thr 167 phosphorylation is unclear (Gould et al., 1991) and its regulatory role in the cell cycle control is somewhat controversial partly because CAK is also involved in general transcription control (Roy et al., 1994; Feaver et al., 1994). Until mitosis is ready to start, the Cdc2-cyclinB complex is held inactive by phosphorylation on the Tyr 15 residue (and also Thr 14) of the Cdc2 molecule. Tyr 15 phosphorylation is catalyzed predominantly by Wee 1 kinase (Featherstone and Russell, 1991; Parker et al., 1992). This phosphorylation is also catalyzed by a minor Mik1 kinase (Lundgren et al., 1991). The inhibitory effect of Thr 14 phosphorylation of $\mathrm{Cdc} 2$ by Myt1 kinase is also reported in vertebrates (Mueller et al., 1995), while the significance of Thr 14 phosphorylation is unclear in fission yeast (Den Haese et al., 1995). Just prior to the onset of $\mathrm{M}$ phase the phosphorylated Tyr 15 and Thr 14 residues are dephosphorylated by
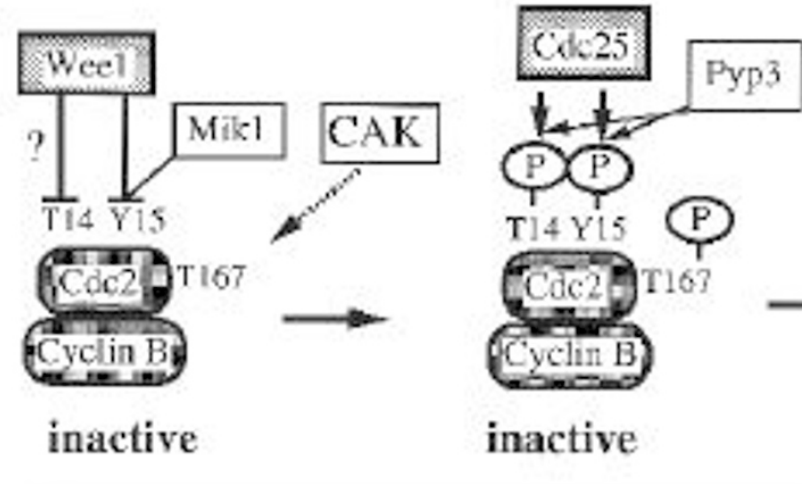

inactive
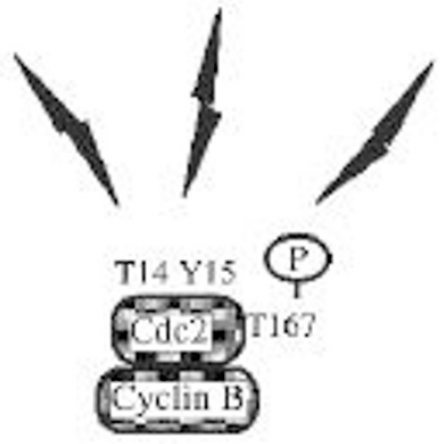

active

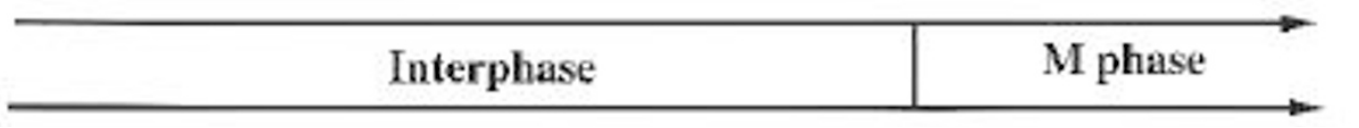

Figure 2. Regulation of Cdc2 activity.

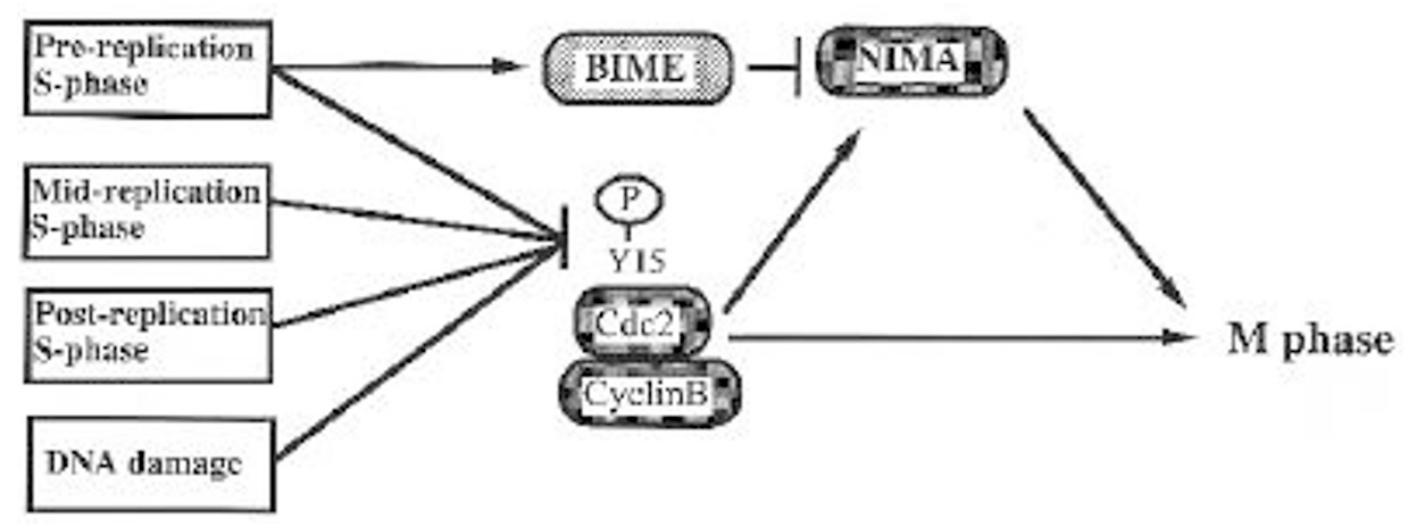

Figure 3. Target of checkpoint regulation. 
the Cdc25 dual tyrosine and threonine phosphatase and a minor Pyp3 phosphatase (Millar et al., 1991, 1992), resulting in rapid activation of the Cdc2-cyclin $B$ complex. The major regulatory event for the final activation of the Cdc2-cyclinB complex seems to be the abrupt dephosphorylation at Tyr 15. During $S$ and G2 phases, the Tyr 15-phosphorylated form of the Cdc2cyclin B complex accumulates (Hayles and Nurse, 1995). Cells in which wild type $\mathrm{Cdc} 2^{\mathrm{Y} 15}$ is replaced by unphosphorylatable $\mathrm{Cdc} 2^{\mathrm{F} 15}$ greatly advances into mitosis with some premature mitotic events (Gould and Nurse, 1989). This phenotype is somewhat similar to that seen when $m i k 1^{+}$and wee $1^{+}$are both inactivated (Lundgren et al., 1991). Both these mutant cells are defective in DNA replication checkpoint control (Enoch et al., 1991; Lundgren et al., 1991). Thus, Tyr 15 phosphorylation of $\mathrm{Cdc} 2$ is a critical target for DNA replication checkpoint control in fission yeast.

However, it is unclear at present how Tyr 15 dephosphorylation is blocked by the checkpoint control system. The blocking may be achieved by either activating Wee1 kinase or inhibiting Cdc25 phosphatase. In fact, overexpression of Cdc25 phosphatase (Enoch and Nurse, 1990) or inactivation of both Wee1 and Mik1 (Lundgren et al., 1991) overrides the arrest imposed by HU. However, cells lacking Wee1 kinase is intact in DNA-replication checkpoint and display no $\mathrm{HU}$ sensitivity (Enoch and Nurse, 1990). Similarly, cells lacking Mik1 kinase have little HU sensitivity (Rowley et al., 1992b). Furthermore, fission yeast cells in which both Wee1 and Cdc25 are deleted can still be arrested by $\mathrm{HU}$, demonstrating that Wee1 and Cdc25 are not the sole target for the checkpoint control (Enoch et al., 1992). In this situation, Tyr 15 of Cdc2 is phosphorylated by minor Mik1 kinase and dephosphorylated by minor Pyp3 phosphatase.

In A. nidulans, NIMX kinase, a homologue of Cdc2, and NIMA kinase are essential for the initiation of mitosis (Osmani et al., 1991; Osmani et al., 1994; Osmani and $\mathrm{Ye}, 1996)$. The regulatory role of Tyr phosphorylation of NIMX is also conserved in this organism (O'Connell et al., 1992). The NIMA kinase is only found in $A$. nidulans, although it is thought that a NIMA-like mitotic pathway may also exist in other organisms (O'Connell et al., 1994; Lu and Hunter, 1995). The activity of NIMA kinase is regulated independently of NIMX kinase but coordinate activation of NIMA and NIMX are required for proper $\mathrm{M}$ phase initiation (Osmani et al., 1991). Like in fission yeast, in $A$. nidulans, Tyr 15 phosphorylation of NIMX is required for slowing down the initiation of mitosis in response to partial inhibition of DNA replication whereas Tyr 15 phosphorylation and BIME are required for $\mathrm{G} 2$ arrest in response to complete inhibition of DNA replication (Ye et al., 1996). Recently, BIME protein homologue was identified as an anaphase-promoting complex in fission yeast (Yamashita et al., 1996), Xenopus (Peters, et al., 1996) and budding yeast (Zachariae et al., 1996), which promotes ubiquitination of target proteins for proteolytic degradation by the 26S proteasome (King et al., 1996).

In mammalian cells, the regulation of Cdc2 at G2/M transition is conserved and the regulatory factors are also identified (Okayama et al., 1996). Expression of the mutant form of Cdc2 unphosphorylatable on both Thr 14 and Tyr 15 does not induce mitosis when DNA replication is completely inhibited, but induces low levels of premature mitosis during progression through $\mathrm{S}$ and $\mathrm{G} 2$ phase (Jin et al., 1996). This phenotypic difference between the complete and partial inhibitions might be explained by whether the cells were blocked in early $S$ before induction of cyclin $\mathrm{B}$ or not. Or like in $A$. nidulans cells, cooperative activation of $\mathrm{Cdc} 2$ and inactivation of BIME-like protein might be required for inducing complete checkpoint defects regardless the state of DNA replication.

Unlike most eukaryotes, DNA replication checkpoint is fully active in budding yeast cells containing unphosphorylatable $\mathrm{Cdc} 28^{\mathrm{F} 15}$, a homologue of $\mathrm{Cdc} 2$, clearly showing that they utilize other mechanisms (Amon et al., 1992; Sorger and Murray, 1992). This difference might be caused by the peculiar feature of budding yeast cells, in which spindle pole body duplication initiates just before $S$ phase begins as pointed already. Unlike in fission yeast, NIMA-like kinase might be the target for checkpoint control in budding yeast. As already noted, the role of Tyr 15 phosphorylation of Cdc2 in checkpoint regulation is highly conserved among many organisms. However, it is also clear that this regulation is not the sole mechanism for DNA replication checkpoint control.

\section{DNA damage-responsive checkpoint control}

The checkpoint sensors and the objects sensed for the detection of DNA damage are not well understood. Damaged DNA is repaired by specific enzymes. For example, when pyrimidine dimers are formed in DNA by UV irradiation, they are detected and excised by the excision repair complex, and the gaps left by excision are filled with DNA polymerase $\delta$. At least the system involving Chk1 kinase, which we have postulated detects aberrant DNA structures rather than factors involved in repair in the previous section, plays a major role in DNA damage-responsive checkpoint control. Cells deleted for $c h k 1^{+}$are defective in DNA damageinduced cell cycle arrest (Walworth et al., 1993). In addition, as described in the previous section, the $\operatorname{rad} 1^{+}, \operatorname{rad} 3^{+}, \operatorname{rad} 9^{+}, \operatorname{rad} 17^{+}, \operatorname{rad} 26^{+}$and $h u s 1^{+}$genes are essential for damage checkpoint control. Very similar to the relationship between $c d s 1^{+}$and these rad 
genes in replication checkpoint control, overproduction of Chk1 partially suppresses the UV sensitivity of at least rad1, rad3 and rad9 mutants, but any of the checkpoint rad genes can not suppress the checkpoint defect of Chk1-minus cells (Murakami and Okayama, unpublished results). In addition, Chk1 autophosphorylates and its autophosphorylation is dependent on the checkpoint rad genes (Walworth and Bernards, 1996). These observations imply that the checkpoint rad genes may be required at least for a full function of Chk1 kinase which is partly compensated by its overproduction. Several observations suggest that Chk1 kinase functions in vicinity of Cdc2 kinase. chk $1^{+}$was initially isolated as a multicopy suppressor of a cold-sensitive cdc2- mutant (Walworth et al., 1993). Chk1 kinase phosphorylates Wee1 kinase in vitro though it does not affect Wee1 kinase activity (O'Connell et al., 1997). Despite its great significance in checkpoint control, structural homologues of Chk1 have not been found in other organisms.

Rad24 protein, a member of the 14-3-3 protein family that has diverse biochemical properties (Aitken et al., 1995) and associates with polyomavirus middle tumor antigen (Pallas et al., 1994), is partly involved in damage but not replication checkpoint (Ford et al., 1994). Cells lacking this gene show $\gamma$-ray sensitivity and partial checkpoint deficiency. On the other hand, Rad25, another member of the 14-3-3 family, seems to have no obvious checkpoint function. Cells lacking both rad $24^{+}$and rad $25^{+}$are lethal. But, it is not known whether this lethal phenotype is caused by checkpoint loss or not. Because of their low level involvement in checkpoint control, their relation to Chk1 and the checkpoint Rad proteins is unknown.

In budding yeast, RAD9, RAD17, RAD24 and MEC3 have been identified as those specifically involved in damage checkpoint control (Weinert et al., 1994). RAD17, RAD24 and MEC3 are required for removal of damaged nucleotide (Lydall and Weinert, 1995). It has been postulated that the resulting single strand DNA region may be detected by a damage checkpoint sensor, such as the system involving Chk1 in fission yeast. Actually, RAD17, a fission yeast homologue of Rad1, encodes a 3'-5' exonuclease (Lydall and Weinert, 1995; Siede et al., 1996a). RAD24, a fission yeast homologue of Rad17 (Griffiths et al., 1995), have a limited homology with RF-C that binds gapped DNA and promotes repair DNA synthesis by DNA polymerase $\delta$. Rad24 protein would be a candidate for a DNA damage recognition protein although its biochemical properties are not known. In contrast, RAD9 is not directly involved in the above process and thought to be activated by a single strand DNA, but its role is unclear (Lydall and Weinert, 1995).

Much like for replication checkpoint control, a key cell cycle target for damage checkpoint control is Cdc2 kinase. However, the involvement of the $\mathrm{Y} 15$ phosphorylation regulation in damage checkpoint control is less clear at present. Cells deficient in Wee1 are sensitive to UV and $\gamma$-ray (Rowley et al., 1992b), but this sensitivity is not caused by the checkpoint deficiency (Barbet and Carr, 1993). Cells having the dominant $c d c 2$ mutation, cdc2-3w, are defective in replication checkpoint control (Enoch and Nurse, 1990) but intact in damage checkpoint control (Al-Khodairy and Carr, 1992). This fact also indicates that the replication and damage checkpoint control systems are mutually independent.

In mammals, several factors are known to be involved in damage checkpoint control. Cells of ataxia telangiectasia are defective in damage checkpoint control in both G1 and G2 phases and show a reduced induction of p53 after $\gamma$-irradiation, suggesting that p53 induction is governed by ATM (Kastan et al., 1992; Lu and Lane, 1993), the causative gene of this hereditary disease, which was recently cloned and shown to have a limited homology with the budding yeast and fission yeast checkpoint rad genes, MEC1 and rad3 ${ }^{+}$(Savitsky et al., 1995). p53 is a recessive oncoprotein and its mutation is associated with malignancy of many human tumor cells (Greenblatt et al., 1994). Cells mutated for p53 are defective in $\gamma$-irradiation induced G1 arrest. p21 was identified as a potent inhibitor of Cdk2 (Xiong et al., 1993), and subsequently found to be transcriptionally regulated by p53 (El-Deiry et al., 1993; Dulic et al., 1993). Consequently, this cascade was initially thought to be the mechanism for damage-induced G1 arrest. But, cells lacking p21 are only partially lost the ability to arrest in G1 (Deng et al., 1995; Brugarolas et al., 1995). In addition to the ATM-p53-p21 cascade (Macleod et al., 1995), the regulation of Cdk4 by tyrosine phosphorylation plays a major role in DNA-damage induced G1 arrest (Terada et al., 1995). The importance of this regulation in damage-induced $\mathrm{G} 1$ arrest was shown by loss of checkpoint function by the expression of unphosphorylatable $\mathrm{Cdk} 4^{\mathrm{F} 17}$. The cells expressing $\mathrm{Cdk} 4^{\mathrm{F} 17}$ suffer severe chromosomal aberration after UV irradiation as a consequence of the inability to arrest in $\mathrm{G} 1$, demonstrating that a damage-responsive checkpoint defect is directly linked to a chromosome aberration in mammals. But, in contrast to the ATMp53-p21 system, this checkpoint system is operative only during cell cycle entry from the stationary phase induced by contact inhibition and serum starvation (Jinno and Okayama, unpublished observation). Thus, at least two independent mechanisms are operated for damage checkpoint control in the G1 phase of mammalian cells.

In the $\mathrm{G} 2$ phase of mammalian cells, tyrosine phosphorylation of Cdc2 is required for DNA damagedependent checkpoint arrest (Kharbanda et al., 1994; Jin et al., 1996). Cells expressing unphosphorylatable $\mathrm{Cdc} 2^{\mathrm{A} 14 \mathrm{~F} 15}$ are partially defective in $\mathrm{G} 2$ arrest when 
irradiated with X-ray, indicating that additional mechanisms are likely to be present, just like in $\mathrm{G} 1$.

In A. nidulans, like in other eukaryotes, the cell cycle target for damage checkpoint control is NIMX (Ye et al., 1997). DNA damage induces rapid phosphorylation of Tyr 15 of NIMX with its inactivation but has little effect on NIMA kinase activity. Cells expressing unphosphorylatable mutant NIMX are deficient in damage checkpoint control.

\section{Endoreplication checkpoint}

Virtually all eukaryotic cells duplicate their genome only once per cell cycle. This rigid control is called endoreplication checkpoint and ensured by at least two restrictions in the cell cycle progression. The first, replication origins are activated only once per $S$ phase. The second, $S$ phase always follows the $M$ phase of the previous cell cycle. Thus, endoreplication checkpoint differs from the former two checkpoints in a sense that these rigid controls are essential parts of the cell cycle progression system.

In fission yeast, the Cdc2-CyclinB complex plays a central role in endoreplication checkpoint control (Nurse, 1994). Inactivation of the Cdc2-Cyclin B kinase activity either by inactivation of $\mathrm{Cdc} 2$ itself or cyclin $\mathrm{B}$, or by overexpression of Rum1, a Cdc2-Cyclin B inhibitor, causes the cell's entry into multiple rounds of $S$ phase (Broek et al., 1991; Moreno and Nurse, 1994; Hayles et al., 1994; Correa-Bordes and Nurse, 1995). In these cases, an endoreplication checkpoint that restricts activation of DNA replication origins once a $S$ phase seems to remain intact. Strangely enough, inactivation of the all known CyclinB in fission yeast cells renders the cells unable to initiate DNA replication (Fisher and Nurse, 1996; Martin-Castellanos et al., 1996). It is postulated that a low activity of Cdc2-CyclinB complex is required for the initiation of $S$ phase whereas high activity is necessary for the start of $M$ phase. On the other hand, overexpression of Cdc18 induces multiple rounds of DNA replication without nuclear division (Nishitani and Nurse, 1995; Muzi-Falconi et al., 1996), indicating that the regulation of Cdc18 activity might be required for the restriction of origin activation once a $S$ phase. Regarding endoreplication checkpoint control, an intricate regulatory cascade among Cdc2-Cyclin B, Rum1 and Cdc18 has been postulated (Jallepalli and Kelly, 1996). In this cascade, Rum1 negatively regulates Cdc2-Cyclin B, which negatively regulates Cdc18, thereby ensuring origin activation once a $S$ phase.

\section{Concluding remarks}

In conclusion, the activity of Cdc2-CyclinB complex is a key to all the checkpoint regulations stated above. The ratio of Tyr 15 phosphorylation of Cdc2 may vary depending on a checkpoint regulation and on organisms. In mammals, the situation is more complex since there are many CDKs and cyclins. However, further studies in yeast will provide invaluable insights to us.

\section{Acknowledgments}

We are grateful to our coworkers for discussions. This work was supported by grants from the Ministry of Science, Education and Culture of Japan and from HFSP.

\section{References}

Aitken, A. (1995) 14-3-3 proteins on the MAP. Trends Biochem Sci. 20: 95-97

Allen, J. B., Zhou, Z.. Siede, W., Friedberg, E. C. and Elledge, S. J. (1994) The SAD1/RAD53 protein kinase controls multiple checkpoints and DNA damage-induced transcription in yeast. Genes Dev. 8: 2401-2015

Al-Khodairy, F., Fotou, E., Sheldrick, K. S., Griffiths, D. J. F., Lehman, A. R., and Carr, A. M. (1994) Identification and characterization of new elements involved in checkpoint and feedback controls in fission yeast. Mol. Biol. Cell 5: 147-160

Al-Khodairy, F. and Carr, A. M. (1992) DNA repair mutants defining G2 checkpoint pathways in Schizosaccharomyces pombe. EMBO J. 11: 1343-1350

Amon, A., Surana, U., Muroff, I. and Nasmyth K. (1992) Regulation of p34 ${ }^{\mathrm{CDC} 28}$ tyrosine phosphorylation is not required for entry into mitosis in S. cerevisiae. Nature 355: 368371

Araki, H., Leem, S. H., Phongdara, A. and Sugino A. (1995) Dpb11, which interacts with DNA polymerase II(epsilon) in Saccharomyces cerevisiae, has a dual role in S-phase progression and at a cell cycle checkpoint. Proc. Natl. Acad. Sci. USA 92: 11791-11795

Barbet, N. C. and Carr, A. M. (1993) Fission yeast wee1 protein kinase is not required for DNA damage-dependent mitotic arrest. Nature 364: 824-827

Broek, D., Bartlett, R., Crawford, K. and Nurse, P. (1991) Involvement of $\mathrm{p} 34^{\mathrm{cdc} 2}$ in establishing the dependency of $S$ phase on mitosis. Nature 349: 388-393

Brugarolas, J., Chandrasekaran, C., Gordon, J. I., Beach, D., Jacks, T. and Hannon, G. J. (1995) Radiation-induced cell cycle arrest compro-mised by p21 deficiency. Nature 377: $552-557$

Buck, V., Russell, P. and Millar, J. B. (1995) Identification of a cdk-activating kinase in fission yeast. EMBO J. 14: 6173-6183

Carr, A. M., Moudjou, M., Bentley, N. J. and Hagan, I. M. (1995) The chk1 pathway is required to prevent mitosis following cell-cycle arrest at start. Curr. Biol. 5: 1179-1190

Correa-Bordes, J. and Nurse P. (1995) p $25^{\text {rum1 }}$ orders S phase and mitosis by acting as an inhibitor of the $\mathrm{p} 34^{\mathrm{cdc} 2}$ mitotic kinase. Cell 83: 1001-1009

Damagnez, V., Makela, T.P. and Cottarel, G. (1995) Schizosaccharo-myces pombe Mop1-Mcs2 is related to mammalian CAK. EMBO J. 14: 6164-6172.

Deng, C., Zhang, P., Harper, J. W., Elledge, S. J. and Leder, P. (1995) Mice lacking p21 $1^{\text {IP1/WAF1 }}$ undergo normal development, but are defective in G1 checkpoint control. Cell 82: 675-684

Den Haese, G. L., Walworth, N., Carr, A. M., and Gould, K. L. (1995) The Wee1 protein kinase regulates T14 phosphorylation of fission yeast Cdc2. Mol. Biol. Cell 6: 371-385.

Diffley, J. F. X. (1996) Once and only once upon a time: specifying and regulating origins of DNA replication in eukaryotic cells. Genes Dev. 10: 2819-2830

Dulic, V., Kaufmann, W. K., Wilson, S. J., TIsty, T. D., Lees, E., Harper, J. W., Elledge, 
S. J. and Reed, S. I. (1994) p53-dependent inhibition of cyclin-dependent kinase activities in human fibroblasts during radiation-induced G1 arrest. Cell 76: 1013-1923

D'Urso, G. and Nurse, P. (1996) S. pombe cdc20 encodes the catalytic subunit of DNA polymerase epsilon. Cold Spring Harbor Symp. 54

D'Urso, G., Grallert, B. and Nurse, P. (1995) DNA polymerase alpha, a component of the replication initiation complex, is essential for the checkpoint coupling $S$ phase to mitosis in fission yeast. J. Cell Sci. 108: 3109-3118

Edgar, B. A. and Lehner, C. F. (1996) Developmental control of cell cycle regulators: a fly's perspective. Science 274: 1646-1652

El-Deiry, W. S., Tokino, T., Velculescu, V. E., Levy, D. B., Parsons, R., Trent, J. M., Lin, D., Mercer, W. E.. Kinzler, K. W. and Vogelstein, B. (1993) WAF1, a potential mediator of p53 tumor suppression. Cell 75: 817-825

Elledge, S. J. (1996) Cell cycle checkpoints; preventing an identity crisis. Science 274: 1664-1672

Enoch, T. Carr, A. M. and Nurse, P. (1992) Fission yeast genes involved in coupling mitosis to completion of DNA replication. Genes Dev. 6: 2035-2046

Enoch, T., Gould, K. L. and Nurse, P. (1991) Mitotic checkpoint control in fission yeast. Cold Spring Harbor Symp. 56: 409-416

Enoch, T. and Nurse, P. (1990) Mutation of fission yeast cell cycle control genes abolishes dependence of mitosis on DNA replication. Cell 60: 665-673

Featherstone, C. and Russell, P. (1991) Fission yeast $p 107^{\text {wee } 1}$ mitotic inhibitor is a tyrosine/serine kinase. Nature 349: 808-811

Feaver, W. J., Svejstrup, J. Q., Henry, N. L. and Kornberg, R. D. (1994) Relationship of CDK-activating kinase and RNA polymerase II CTD kinase TFIIH/TFIIK. Cell 79: 11031109

Fisher, D. L. and Nurse P. (1996) A single fission yeast mitotic cyclin B p34 $4^{\text {cdc2 }}$ kinase promotes both S-phase and mitosis in the absence of G1 cyclins. EMBO J. 15: 850-860

Ford, J. C., Al-Khodairy, F., Fotou, E., Sheldrick, K. S., Griffiths, D. F. J. and Carr, A. M. (1994) 14-3-3 protein homologs required for the DNA damage checkpoint in fission yeast. Science 265: 533-535

Francesconi, S., De Recondo, A. M. and Baldacci, G. (1995) DNA polymerase delta is required for the replication feedback control of cell cycle progression in Schizosaccharomyces pombe. Mol. Gen. Genet. 246: 561-569

Gould, K. L., Moreno, S., Owen, D. J., Sazer, S. and Nurse P. (1991) Phosphorylation at Thr167 is required for Schizosaccharomyces pombe p34 $4^{\text {cdc2 }}$ function. EMBO J. 10: 3297-3309

Gould, K. L. and Nurse, P. (1989) Tyrosine phosphorylation of the fission yeast $c d c 2^{+}$ protein kinase regulates entry into mitosis Nature $342: 39-45$

Grallert, B. and Nurse, P. (1996) The ORC1 homologue orp1 in fission yeast plays a key role in regulating onset of $S$ phase. Genes Dev. 10: 2644-2654

Greenblatt, M. S., Bennett, W. P., Hollstein, M. and Harris, C. C. (1994) Mutations in the p53 tumor suppressor gene: clues to cancer etiology and molecular pathogenesis. Cancer Res. 54: 4855-4878

Griffiths, D. J., Barbet, N. C., McCready, S. and Lehmann, A. R. and Carr A. M. (1995) Fission yeast rad17: a homologue of budding yeast RAD24 that shares regions of sequence similarity with DNA polymerase accessory proteins. EMBO J. 14: 5812-5823

Hartwell, L. H. and Kastan, M. B. (1994) Cell cycle control and cancer. Science 266: 1821-1828

Hartwell, L. and Weinert, T. (1989) Checkpoints: controls that ensure the order of cell cycle events. Science 246: 629-634

Hayles, J. and Nurse, P. (1995) A pre-start checkpoint preventing mitosis in fission yeast acts independently of $\mathrm{p} 34^{\text {cdc2 } 2}$ tyrosine phosphorylation. EMBO J. 14: 2760-2771

Hayles, J., Fisher, D., Woollard, A. and Nurse P. (1994) Temporal order of S phase and mitosis in fission yeast is determined by the state of the $\mathrm{p} 34^{\mathrm{cdc2}}$-mitotic B cyclin complex. Cell 78: 813-822

Jallepalli, P. V. and Kelly ,T. J. (1996) Rum1 and Cdc18 link inhibition of cyclindependent kinase to the initiation of DNA replication in Schizosac-charomyces pombe. Genes Dev. 10: 541-552

Jin, P., Gu, Y. and Morgan, D. O. (1996) Role of inhibitory CDC2 phosphorylation in radiation-induced $\mathrm{G} 2$ arrest in human cells. J. Cell Biol. 134: 963-970

Kastan, M. B., Zhan, Q., el-Deiry, W. S., Carrier, F., Jacks, T., Walsh, W. V., Plunkett, B. S., Vogelstein, B. and Fornace, A. J. Jr. (1992) A mammalian cell cycle checkpoint pathway utilizing p53 and GADD45 is defective in ataxia-telangiectasia. Cell 71: 587597

Kato, R. and Ogawa, H. (1994) An essential gene, ESR1, is required for mitotic cell growth, DNA repair and meiotic recombination in Saccharo-myces cerevisiae. Nucl. Acid Res. 22: 3104-3112.

Kelly, T. J., Martin, G. S., Forsburg, S. L., Stephen, R. J., Russo, A. and Nurse, P. (1993) The fission yeast $c d c 18^{+}$gene product couples S phase to START and mitosis. Cell 74: 371-382

Kharbanda, S., Saleem, A., Datta, R., Yuan, Z., Weichselbaum, R. and Kufe, D. (1994) lonizing radiation induces rapid tyrosine phosphorylation of $\mathrm{p} 34^{\text {cdc2 }}$. Cancer Res. 54 $1412-1414$

King, R. W., Deshaies, R. J., Peters, J.-M. and Kirschner, M. W. (1996) How proteolysis drives the cell cycle. Science 274: 1652-1659

Ko, L. J. and Prives, C. (1996) p53: puzzle and paradigm. Genes Dev. 10: 1054-1072

Leatherwood, J., Lopez-Girona, A. and Russell, P. (1996) Interaction of Cdc2 and Cdc18 with a fission yeast ORC2-like protein. Nature 379: 360-363

Lieberman, H. B., Hopkins, K. M., Laverty, M. and Chu, H. M. (1992) Molecular cloning and analysis of Schizosaccharomyces pomberad9, a gene involved in DNA repair and mutagenesis. Mol. Gen. Genet. 232: 367-376

Lu, K. P. and Hunter, T. (1995) Evidence for a NIMA-like mitotic pathway in vertebrate cells. Cell 81: 413-424

Lu, X. and Lane, D. P. (1993) Differential induction of transcriptionally active p53 following UV or ionizing radiation: defects in chromosome instability syndromes? Cell 75: $765-778$

Lundgren, K., Walworth, N., Booher, R., Dembski, M., Kirschner, M. and Bearch, D. (1991) mik1 and wee1 cooperate in the inhibitory tyrosine phosphorylation of cdc2. Cell 64: 1111-1122

Lydall, D. and Weinert, T. (1995) Yeast checkpoint genes in DNA damage processing: implications for repair and arrest. Science 270: 1488-1491

Macleod, K. F., Sherry, N., Hannon, G., Beach, D., Tokino, T., Kinzler, K., Vogelstein, B. and Jacks, T. (1995) p53-dependent and independent expression of p21 during cell growth, differentiation, and DNA damage. Genes Dev. 9: 935-944

MacNeill, S. A., Moreno, S., Reynolds, N., Nurse, P. and Fantes, P. A. (1996) The fission yeast $\mathrm{Cdc1}$ protein, a homologue of the small subunit of DNA polymerase $d$, binds to Pol3 and Cdc27. EMBO J. 15: 4613-4628

Maiorano, D., van Assendelft, G. B. and Kearsey, S. E. (1996) Fission yeast cdc21, a member of the MCM protein family, is required for onset of $S$ phase and is located in the nucleus throughout the cell cycle. EMBO J. 15: 861-872

Martin-Castellanos, C., Labib, K. and Moreno, S. (1996) B-type cyclins regulate G1 progression in fission yeast in opposition to the p $25^{\text {rum1 }} \mathrm{cdk}$ inhibitor. EMBO J. 15: 839849

Masai, H., Miyake, T. and Arai K. (1995) $h s k 1^{+}$, a Schizosaccharomyces pombe gene related to Saccharomyces cerevisiae $\mathrm{CDC7}$, is required for chromosomal replication. EMBO J. 14: 3094-3104

Millar, J. B., Lenaers, G. and Russell ,P. (1992) Pyp3 PTPase acts as a mitotic induce 
in fission yeast. EMBO J. 11: 4933-4941

Millar, J. B., McGowan, C. H., Lenaers, G., Jones, R. and Russell, P. (1991) p80 cdc25 mitotic inducer is the tyrosine phosphatase that activates $p 34^{c d c 2}$ kinase in fission yeast. EMBO J. 10: 4301-4309

Moreno, S. and Nurse, P. (1994) Regulation of progression through the G1 phase of the cell cycle by the rum $1^{+}$gene. Nature $367: 236-242$

Moreno, S., Hayles, J. and Nurse, P. (1989) Regulation of $p 34^{\text {cdc2 }}$ protein kinase during mitosis. Cell 58: 361-372

Mueller, P. R., Coleman, T.R., Kumagai, A. and Dunphy, W. G. (1995) Myt1: a membrane-associated inhibitory kinase that phosphorylates $\mathrm{Cdc} 2$ on both threonine-14 and tyrosine-15. Science 270: $86-90$

Murakami, H. and Okayama, H. (1995) A kinase from fission yeast responsible for blocking mitosis in S phase. Nature 374: 817-819

Muzi-Falconi, M., Brown, G. W. and Kelly, T. J. (1996) $c d c 18^{+}$regulates initiation of DNA replication in Schizosaccharomyces pombe. Proc. Natl. Acad. Sci. USA 93: 15661570

Muzi-Falconi, M. and Kelly T. J. (1995) Orp1, a member of the Cdc18/ Cdc6 family of Sphase regulators, is homologous to a component of the origin recognition complex. Proc. Natl. Acad. Sci. USA 92: 12475-12479

Nasmyth, K. (1996) Viewpoint: putting the cell cycle in order. Science 274: 1643-1645

Navas, T. A,. Zhou, Z. and Elledge, S. J. (1995) DNA polymerase epsilon links the DNA replication machinery to the $S$ phase checkpoint. Cell 80: 29-39

Nishitani, H. and Nurse P. (1995) p65 ${ }^{\text {cdc18 }}$ plays a major role controlling the initiation of DNA replication in fission yeast. Cell 83: 397-405

Nurse, P. (1994) Ordering S phase and M phase in the cell cycle. Cell 79: 547-550

Nurse, P. (1990) Universal control mechanism regulating onset of M-phase, Nature 344: 503-508

O'Connell, M. J., Raleigh, J. M., Verkade, H. M. and Nurse, P. (1997) Chk1 is a wee1 kinase in the $\mathrm{G} 2$ DNA damage checkpoint inhibiting cdc2 by $Y 15$ phosphorylation. EMBO J. 16: $545-554$

O'Connell, M. J., Norbury, C. and Nurse, P. (1994) Premature chromatin condensation upon accumulation of NIMA. EMBO J. 13: 4926-4937

O'Connell, M. J., Osmani, A. H., Morris, N. R. and Osmani, S. A. (1992) An extra copy of nimE ${ }^{\text {cyclinB }}$ elevates pre-MPF levels and partially suppresses mutation of nim $^{\mathrm{cdc} 25}$ in Aspergillus nidulans. EMBO J. 11: 2139-2149

Okayama, H., Nagata, A., Jinno, S., Murakami, H., Tanaka, K. and Nakashima, N. (1996) Cell cycle control in fission yeast and mammals: identification of new regulatory mechanisms. Adv. Cancer Res. 69: 17-62

Osmani, S. A. and Ye, X. S. (1996) Cell cycle regulation in Aspergillus by two protein kinases. Biochem. J. 317: 633-641

Osmani, A. H., van Peij, N., Mischke, M., O'Connell, M. J. and Osmani, S. A. (1994) A single $\mathrm{p} 34^{\mathrm{cdc} 2}$ protein kinase (encoded by nim $\mathrm{X}^{\mathrm{cdc} 2}$ ) is required at $\mathrm{G} 1$ and $\mathrm{G} 2$ in Aspergillus nidulans. J. Cell Sci. 107: 1519-1528

Osmani, A. H., McGuire, S. L. and Osmani, S. A. (1991) Parallel activation of the NIMA and $p 34^{\text {cdc2 }}$ cell cycle-regulated protein kinases is required to initiate mitosis in $A$. nidulans. Cell 67: 283-291

Pallas, D. C., Fu, H., Haehnel, L. C., Weller, W., Collier, R. J. and Roberts, T. M. (1994) Association of polyomavirus middle tumor antigen with 14-3-3 proteins. Science 265: $535-537$

Parker, L. L., Atheron-Fessler, S. and Piwnica-Worms, H. (1992) p107 $7^{\text {wee } 1}$ is a dualspecificity kinase that phosphorylates $\mathrm{p} 34^{\mathrm{cdc} 2}$ on tyrosine 15. Proc. Natl. Acad. Sci. USA 89: $2917-2921$

Peters, J. M., King, R. W., Hoog, C. and Kirschner, M. W. (1996) Identification of BIME as a subunit of the anaphase-promoting complex. Science 274: 1199-1201

Rowley, R., Subramani, S. and Young, P. G. (1992a) Checkpoint controls in Schizosaccharomyces pombe: rad1. EMBO J. 11: 1335-1342

Rowley, R., Hudson, J. and Young, P.G. (1992b) The wee1 protein kinase is required for radiation-induced mitotic delay. Nature 356: 353-355

Roy, R., Adamczewski, J. P., Seroz, T., Vermeulen, W., Tassan, J. P. Schaeffer, L., Nigg, E. A., Hoeijmakers, J. H. and Egly, J. M. (1994) The MO15 cell cycle kinase is associated with the TFIIH transcription-DNA repair factor. Cell 79: 1093-1101

Saka, Y. and Yanagida, M. (1993) Fission yeast $c u t 5^{+}$, required for S phase onset and $M$ phase restraint, is identical to the radiation-damage repair gene rad4 $4^{+}$. Cell $74: 383$ 393

Sanchez, Y., Desany, B. A., Jones, W. J., Liu, Q., Wang, B. and Elledge, S. J. (1996) Regulation of RAD53 by the ATM-like kinases MEC1 and TEL1 in yeast cell cycle checkpoint pathways. Science 271: 357-360

Savitsky, K., Bar-Shira, A., Gilad, S., Rotman, G., Ziv, Y., Vanagaite, L., Tagle, D. A., Smith, S., Uziel, T., Sfez, S., Ashkenezi, M., Pecker, I., Frydman, M., Harnik, R. Patanjali, S. R., Simmons, A., Clines, G. A., Sartiel, A., Gatti, R. A., Chessa, L., Sanal, O., Lavin, S. M., Lovett, M., Collins, F. S. and Shilo, Y. (1995) A single ataxia telangiectagia gene with a product similar to PI-3 kinase. Science 268: 1749-1752 Sherr, C. J. (1996) Cancer cell cycles. Science 274: 1672-1677

Siede, W., Nusspaumer, G., Portillo, V., Rodriguez, R. and Friedberg, E. C. (1996a) Cloning and characterization of RAD17, a gene controlling cell cycle responses to DNA damage in Saccharomyces cerevisiae. Nucl. Acid Res. 24: 1669-1675

Siede, W., Allen, J. B., Elledge, S. J. and Friedberg, E. C. (1996b) The Saccharomyces cerevisiae MEC1 gene, which encodes a homolog of the human ATM gene product, is required for $\mathrm{G} 1$ arrest following radiation treatment. J. Bacteriol. 178: 5841-5843

Sorger, P. K. and Murray, A. W. (1992) S-phase feedback control in budding yeast independent of tyrosine phosphorylation of p34 ${ }^{\text {cdc28 }}$. Nature $355: 365-368$

Stern, D. F., Zheng, P., Beidler, D. R. and Zerillo, C. (1991) Spk1, a new kinase from Saccharomyces cerevisiae, phosphorylates proteins on serine, threonine, and tyrosine. Mol. Cell. Biol. 11: 987-1001

Stillman, B. (1996) Cell cycle control of DNA replication. Science 274: 1659-1664

Sugimoto, K., Shimomura, T., Hashimoto K., Araki H., Sugino A. and Matsumoto, K (1996) Rfc5, a small subunit of replication factor C complex, couples DNA replication and mitosis in budding yeast. Proc. Natl. Acad. Sci USA 93: 7048-7052

Sugino, A. (1995) Yeast DNA polymerases and their role at the replication fork. Trends Biochem. Sci. 20: 319-323

Sun, Z., Fay, D. S., Marini, F., Foiani, M. and Stern, D. F. (1996) Spk1/Rad53 is regulated by Mec1-dependent protein phosphorylation in DNA replication and damage checkpoint pathways. Genes Dev. 10: 395-406

Terada, Y., Tatsuka, M., Jinno, S. and Okayama, H. (1995) Requirement for tyrosine phosphorylation of cdk4 in G1 arrest induced by ultraviolet irradiation. Nature 376: 358362

Walworth, N. C. and Bernards, R. (1996) rad-dependent response of the chk1-encoded protein kinase at the DNA damage checkpoint. Science 271: 353-356

Walworth, N. C., Davey, S. and Beach, D. (1993) Fission yeast chk1 protein kinase links the rad checkpoint pathway to cdc2. Nature 363: 368-371

Weinert, T. A., Kiser, G. L. and Hartwell, L. H. (1994) Mitotic checkpoint genes in budding yeast and the dependence of mitosis on DNA replication and repair. Genes Dev. 8: 652-665

Xiong, Y., Hannon, G. J., Zhang, H., Casso, D., Kobayashi, R. and Beach, D. (1993) p21 is a universal inhibitor of cyclin kinases. Nature 366: 701-704

Yamashita, M. Y., Nakaseko, Y., Samejima, I., Kumada, K., Yamada, H., Michaelson, D. and Yanagida, M. (1996) 20S cyclosome complex formation and proteolytic activity 
inhibited by the CAMP/PKA pathway. Nature 384: 276-279

Ye, X. S., Fincher, R. R., Tang, A. and Osmani, S. A. (1997) The G2/M DNA damage checkpoint inhibits mitosis through Tyr 15 phosphorylation of $\mathrm{p} 34^{\mathrm{cdc} 2}$ in Aspergillus nidulans.EMBO J. 16: 182-192

Ye, X. S., Fincher, R. R., Tang, A., O'Donnell, K. and Osmani, S. A. (1996) Two Sphase checkpoint systems, one involving the function of both BIME and Tyr 15 phosphorylation of $\mathrm{p} 34^{\mathrm{cdc} 2}$, inhibit NIMA and prevent premature mitosis. EMBO J. 15 : 3599-3610

Zachariae, W., Shin, T. H., Galova, M., Obermaiet, B. and Nasmyth, K. (1996) Identification of subunits of the anaphase-promoting complex of Saccharomyces cerevisiae. Science 274: 1201-1204

Zheng, P., Fay, D. S., Burton, J., Xiao, H., Pinkham, J. L. and Stern, D. F. (1993) SPK1 is an essential S-phase-specific gene of Saccharo-myces cerevisiae that encodes a nuclear serine/threonine/tyrosine kinase. Mol. Cell. Biol. 13: 5829-5842 